\title{
"Não faz mal pensar que não se está só": estilo, produção cultural e feminismo entre as minas do rock em São Paulo*
}

\author{
Regina Facchini**
}

\section{Resumo}

Este artigo procura contribuir para a compreensão das diversas formas assumidas pelo ativismo político no Brasil contemporâneo, enfocando especificamente a intersecção entre política e estilo no feminismo das minas do rock. Para tanto, recupera material fruto de pesquisa etnográfica realizada entre 2004 e 2007 na cena paulistana do rock de mina. A análise propõe considerar o caráter espetacular do estilo como forma de "dar-se a ver" e comunicarse, assim como tomar em conta as múltiplas relações de poder nas quais se inscreve o que é comunicado. Desse modo, sugere pensar os estilos como operadores de diferenças, levando em conta que não são produzidos por sujeitos pré-dados, que agem de forma inteiramente consciente em relação aos efeitos provocados por dada composição de aparência, atitude e música. Ao contrário, considera que os sujeitos se constituem no processo de citar e deslocar normas sociais e que isso pode se dar no processo de composição de um estilo.

Palavras-chave: Movimentos Sociais, Feminismo, Juventude, Estilos, Interseccionalidades, Agência Social.

\footnotetext{
* Recebido para publicação em fevereiro de 2011, aceito em abril de 2011. Este artigo é uma versão modificada e atualizada do capítulo "Dykes numa rede de minas do rock" que integra minha tese de doutorado (Facchini, 2008). Agradeço a Isadora Lins França pela leitura atenta e generosa de versões deste artigo, aos diálogos com Maria Filomena Gregori, Mariza Corrêa e Julio Simões à época da tese, às sugestões de Carolina Parreiras e de Bruna Mantese e ao CNPq, que apoiou financeiramente a pesquisa que originou este material. Dedico este artigo a Mariza Corrêa e a todas as minas do rock que me acolheram no período de campo, especialmente Elisa Gargiulo, Geisa França, Kerby Ferris, Claudia Rom e Bruna Angrisani.

** Doutora em Ciências Sociais pela UNICAMP, pesquisadora do Núcleo de Estudos de Gênero - Pagu e professora participante do Programa de Doutorado em Ciências Sociais, ambos da Unicamp, colaboradora do movimento LGBT paulista e integrante do Coletivo Espaço B.rfacchini@uol.com.br
}

cadernos pagu (36), janeiro-junho de 2011:117-153. 
"Não faz mal pensar que não se está só"

"Doesn't hurt to think you're not alone": style, cultural production, and feminism among the riot grrrls in São Paulo

\begin{abstract}
This article aims to offer a contribution to the understanding of the various forms assumed by political activism in contemporary Brazil, focusing specifically on the intersection between politics and style in the riot grrrls' feminism. In order to do that, it rescues material originated from ethnographic research carried out between 2004 and 2007 in the São Paulo riot grrrls' scene. The research coincides with a specific moment of this scene, marked by its expansion, indicated by the growth of the volume of activities and of its visibility, and by the organization of annual editions of the LadyFest Brasil - a cultural festival devised by women and for women that resumed and symbolized the scene's spirit, also integrating it to the calendar of international festivals of the same kind. The analysis proposes to consider the spectacular character of the style as a form of "making oneself visible" and of communicating with one another, as well as to consider the multiple power relations in which the communicated message is inscribed. Therefore, it suggests thinking the styles as operators of difference, taking into account the fact that they are not produced by pre-given subjects, who act in complete awareness of the effects caused by a given composition of appearance, attitude and music. On the contrary, this article considers that the subjects are constituted in the process of quoting and dislocating social norms, and that this may be given in the process of composition of a style.
\end{abstract}

Key Words: Social Movements, Feminism, Youth, Styles, Intersections, Social Agency. 
Regina Facchini

Um de vocês vai dizer que não viu nada, não ouviu nada. Um de vocês vai me dizer 'vai devagar, sem acusar'.

A violência se faz,

A indiferença se faz,

A intolerância se faz sem testemunha.

Dentro de casa, nas ruas do subúrbio,

Dentro de casamento e nas delegacias.

Não faz mal pensar que não se está só.

Um de vocês vai dizer que não viu nada, não ouviu nada.

Um de vocês vai me dizer 'vai devagar, sem acusar'. E também sofrem as ricas disfarçadas, as mães executivas e as presidiárias.

O grito mudo das filhas do subúrbio penetra nas entranhas do teu ouvido surdo.

Não faz mal pensar que não se está só. (Filhas, mães e irmãs; Dominatrix)

A frase que serve de título a este artigo é parte do refrão da música Filhas, mães e irmãs da banda Dominatrix, uma das precursoras da cena ${ }^{1}$ riot grrrl, ou simplesmente das minas do

1 A noção de "cena" vem sendo usada para estabelecer relações entre dados gostos e estilos musicais e determinados territórios. Essa relação se estabelece de modo a preservar o caráter elástico e invisível das fronteiras de supostas "unidades culturais" (referindo-se ora à cena local, ora a uma cena regional, nacional ou internacional). Tal noção tem sido usada como alternativa a formulações como "subculturas", para acionar um sentido de dinamismo de tais "unidades" (Straw, 2006). O uso de cena neste trabalho tem um caráter instrumental, a fim de situar, territorialmente, determinadas redes sociais (Barnes, 1987) e porções de uma rede ampliada que transpõe limites geográficos. Tal uso é semelhante ao que se faz de cena como categoria êmica em várias redes sociais que se estruturam em torno de gostos musicais, inclusive na formada pelas minas do rock. Adotei como convenções neste artigo a utilização de grafia em itálico para termos êmicos, falas de entrevistadas incluídas no interior de parágrafos e estrangeirismos. Conceitos, classificações aproximativas feitas pela autora - como o uso de categorias do IBGE para referência a cor ou de categorias como "masculina" ou "feminina" para referir atributos corporais de gênero observados -, bem como citações de autores no interior de parágrafos são indicados por aspas. Documentos ou páginas de internet consultados e citados no decorrer do artigo foram indicados nas notas de rodapé. Os nomes das entrevistadas são fictícios. 
"Não faz mal pensar que não se está só"

rock, no Brasil. Na internet, é possível encontrar a letra da música em vários sites especializados na divulgação de letras nacionais e estrangeiras e várias versões de vídeo. Entre essas versões há as de shows, realizados em espaços privados, como o Inferno Club na Rua Augusta, ou em espaços públicos como o Centro Cultural São Paulo, o Centro Cultural da Juventude ou no espaço cultural que abriga a Verdurada, evento periódico da cena straight edge ${ }^{2}$ local. Mas há também uma versão mais clean veiculada no Jornal da MTV e uma chamada para um show-ato pelo fim da violência contra as mulheres, realizado em dezembro de 2010, a partir de um projeto da ONG Católicas Pelo Direito de Decidir apoiado pela Secretaria de Políticas para Mulheres. ${ }^{3}$ Em parte dessas versões, a banda toda ou apenas sua vocalista, Elisa Gargiulo, são acompanhadas por Vange Leonel, cantora, escritora e colunista, que foi ativista do movimento lésbico no final dos anos 1970, seguiu sua carreira artística e desde o final dos anos 1990 escrevia também sobre homossexualidade e sobre cultura para a Revista da Folha e para o site Mix Brasil.

2 A Verdurada é, segundo seu site, um "evento, que acontece bimestralmente em São Paulo desde 1996 [...e] consiste na apresentação de bandas quase sempre de hardcore e palestras sobre assuntos políticos, além de oficinas, debates, exposição de vídeos e de arte de conteúdo político e divergente. Ao fim do show é distribuído um jantar totalmente vegetariano." (www.verdurada.org). A Verdurada é o evento mais importante da cena straight edge em São Paulo, por oposição a churrascadas ou cervejadas. De acordo com Bruna Mantese Souza, os straight edges são descendentes diretos do punk, mais especificamente do hardcore americano, compartilhando o estilo musical e o visual "agressivo", marcado pelo uso de modificações corporais, como tatuagens e piercings. Apresentam, porém diferenças significativas em relação aos punks: são contrários ao consumo de drogas e álcool $e$ avessos à permissividade sexual e à homofobia, um dos traços mais característicos do estilo na cena é a adesão ao vegetarianismo ou ao veganismo (Souza, 2006). Além de não consumirem produtos de origem animal, bem como álcool e outras drogas, os straight edges também não consomem cosméticos de origem animal e/ou testados em animais.

3 Sobre o projeto Sede de quê? da organização feminista Católicas pelo Direito de Decidir, ver o blog: http://sededeque.com.br/ . 
Um breve olhar para essas referências, ligadas a onde se pode encontrar apenas uma música da banda mais conhecida da cena brasileira, permite entrever um campo que inclui atores como o movimento feminista e o LGBT, cenas político-culturais juvenis como a dos straight edges, organizações feministas como Católicas pelo Direito de Decidir, órgãos governamentais como a Secretaria Especial de Políticas para Mulheres, empresas da área de comunicação e cultura como a MTV, a Folha de S. Paulo e o Mix Brasil. É num campo híbrido como esse, que vemos moverem-se atualmente atores e questões afetas tanto à produção cultural quanto ao ativismo político.

Variações na forma de apresentação podem ser notadas nas diversas versões em que vídeos da referida música podem ser encontrados na internet. Na primeira delas, a música e sua letra são em si a mensagem divulgada massivamente numa emissora da grande mídia voltada especificamente para o segmento juvenil: a banda toca em cenário de estúdio da MTV, com os enquadramentos de câmera característico da emissora. ${ }^{4}$ Postado duas vezes no site de compartilhamento de vídeos youtube.com, cada uma das postagens conta com mais de 10 mil acessos. A peça de marketing viral ${ }^{5}$ circulou por redes mais específicas, próximas ao ativismo feminista e LGBT, por meio da internet, $e$ fazia parte da divulgação do show pelo fim da violência contra a mulher, realizado gratuitamente no Parque do Carmo, na zona Leste da cidade, no qual Dominatrix e Vange Leonel dividiram o

${ }^{4}$ Dominatrix - Filhas, Mães, Irmãs. (Live - jornal da MTV) [http:// www.youtube.com/watch?v=wSUcrfumW6Q - acesso em 25/03/2011].

${ }^{5}$ Marketing viral é um termo usado para se referir à estratégia de marketing que utiliza redes sociais na internet, procurando produzir um aumento exponencial do conhecimento acerca de determinada marca ou informação por meio de pessoas que, articuladas em redes, vão repassando uma peça (um email, post em blog, twitter ou videoclip) aos seus contatos. Essa estratégia já havia sido usada pelas minas do rock quando da criação de uma vinheta de divulgação do site Quitéria [http://www.youtube.com/watch?v=KtYW2zexs8s - acesso em 25/03/2011] e essa parece ser a lógica a partir da qual blogs, fotologs e redes sociais na internet são usados pelas garotas na cena. 
"Não faz mal pensar que não se está só"

palco com Leci Brandão, Hip Hop Mulher e Faa Morena. A chamada dizia: "A música pode juntar as pessoas. Com mais volume, ela pode parar a violência contra as mulheres!" ${ }^{6} \mathrm{O}$ vídeo gravado numa Verdurada de $2008^{7}$ mostra um cenário típico de show na cena punk hardcore: palco pequeno, platéia lotada, centenas de jovens em pé, garotos e garotas subindo à frente do palco para saltar em moshs por cima do público durante a execução das músicas, fazendo com que os corpos, sustentados por ombros, braços e mãos, deslizem por cima do público na frente do palco. Nesse contexto, há lugar para uma fala de apresentação no início da música e ela é direcionada às garotas $e$ aos garotos presentes ao show:

A música que a gente vai fazer agora é da fase nova da banda, cantando em português, e uma música que fala de violência. (...) E, na época que a gente fez essa música, um mês depois, aconteceu o caso de que uma menina de 15 anos foi jogada dentro de uma cela com mais de 20 presos na região norte do país, foi estuprada sequencialmente por todos eles e demorou mais de um mês pras pessoas saberem dessa situação. Isso causa uma revolta muito grande na gente, justo num momento em que a gente está querendo falar mais de violência e, de uma maneira mais clara, em português, porque a gente acha importante. Então, esta música, eu queria dedicar a todas as mulheres que cotidianamente resistem contra a violência doméstica [gritos das garotas na platéia] e a todos os rapazes que um dia foram sensíveis à causa das mulheres e que quiseram se juntar a nós. Esta música é pra vocês, também [gritos dos rapazes e aplausos gerais] (apresentação da música Filhas,

${ }^{6}$ Dominatrix \& Vange Leonel - show pelo fim da violência contra as mulheres 1/3. [http://www.youtube.com/watch?v=FWD77W0hYx8 - acesso em 25/03/2011]

7 Dominatrix - Filhas, Mães e Irmãs (pt.03/18). [http://www.youtube.com/ watch?v=OLYgCDbr9Xo - acesso em 25/03/2011] 
Regina Facchini

mães e irmãs, show da banda Dominatrix na Verdurada, São Paulo, Jabaquara, 08/01/2008).

Este artigo procura oferecer uma contribuição para a compreensão das diversas formas assumidas pelo ativismo político no Brasil contemporâneo - sobretudo o que se dá entre jovens que se identificam, entre outras coisas, como feministas -, especialmente no que diz respeito a suas conexões com cenas de produção cultural. Para tanto, recupera material fruto de pesquisa etnográfica realizada entre 2004 e 2007 na cena paulistana do rock de mina. A pesquisa coincide exatamente com um momento específico desta cena, marcado por sua expansão, como indica o aumento da quantidade de atividades e de sua visibilidade. Não por acaso, 2004 foi o ano do primeiro LadyFest Brasil, festival político-cultural feito por mulheres e para mulheres que condensava e simbolizava o espírito desta cena, integrando-a também ao calendário de festivais internacionais de mesmo tipo. ${ }^{8}$

\section{Contextualizando: o riot grrrl, as minas do rock em meados dos anos 2000 e o LadyFest Brasil}

As minas do rock são integrantes de uma cena internacional conhecida como riot grrrl $9^{9}$ e organizam-se numa rede não muito permeável de meninas de 14 a 20 e poucos anos que se estende

\footnotetext{
8 Michelle Alcântara Camargo (2010) menciona que esse período foi identificado como parte de uma "segunda geração" de minas do rock por algumas das integrantes das primeiras bandas e iniciativas. Reconhecem, assim, a formação de um público de mulheres no interior da cena e um processo de renovação e chegada de novas integrantes, trazendo consigo também novas ênfases $e$ preocupações. Segundo a autora, essa "segunda geração" seria marcada por um interesse muito pronunciado por questões relacionadas à sexualidade e à homofobia (termo popularizado a partir de meados da década de 2000 no Brasil $e$ incorporado por essas jovens).

9 Estilo voltado para mulheres jovens, cujo surgimento no início dos anos 1990, nos EUA, é marcado pelo lançamento, pela banda de rock Bikini Kill, do fanzine feminista "Riot Grrrls".
} 
"Não faz mal pensar que não se está só"

pelas principais capitais brasileiras e conecta-se a roteiros internacionais como Washington, Olympia, Portland, Seattle e outras cidades dos Estados Unidos. As referências do estilo vêm da cena punk norte-americana e sua politização explícita parece acompanhar outras vertentes do punk.

A primeira banda da cena brasileira, Dominatrix, de São Paulo, começou sua trajetória há quinze anos. Em 1998, surgia a Bulimia, também das primeiras bandas brasileiras, que inaugurava a cena em Brasilia. Por meio de festivais e do incentivo a que outras garotas tocassem, a cena foi se expandindo. As primeiras bandas consideravam seu som como punk rock. Atualmente, no rock de mina do Brasil, o punk e o hardcore não são mais as únicas referências musicais, havendo variação considerável entre as sonoridades produzidas, com vários graus de incorporação de estilos musicais relacionados ao rock e à música eletrônica.

As riot grrrls se consideram feministas, aderindo a uma versão de feminismo que se opõe ao "machismo" da cena punk e estabelece um tipo de "fraternidade feminina", na qual as relações sexuais e afetivas entre mulheres são uma expressão bastante valorizada. A letra do hino "Punk rock não é só pro seu namorado", da banda Bulimia, nos remete um pouco ao ambiente do início da cena:

O que te impede de lutar?

O que te impede de falar?

Pare de se esconder

Você não é pior que ninguém

Punk rock não é só pro seu namorado

Você sempre quis tocar

Você sempre quis andar de skate

Você que sempre quis quis quis

Você não é um enfeite!

Punk rock não é só pro seu namorado

Faça o que tiver vontade

Mostre o que você pensa

Tenha a sua personalidade 
Regina Facchini

Não se esconda atrás de um homem (Punk rock não é só para o seu namorado, Bulimia, 1998)

Entrei em contato com as minas do rock no início de 2004, quando fui convidada por uma colaboradora da pesquisa de doutorado, para um show no Hangar 110. Tratava-se da primeira edição do LadyFest Brasil, definido por uma de suas organizadoras como um festival de cultura jovem feminista feito exclusivamente por mulheres e também direcionado para mulheres, que incluía shows de bandas de meninas, exposições, debates e oficinas sobre temas ligados ao feminismo e debatidos na cena, além de oficinas musicais e de esportes, como skate para meninas. Parte das atividades, especialmente oficinas e debates, costumavam ser de frequência exclusiva para garotas. Os shows e exposições eram abertos.

Entre as organizadoras do festival, estavam garotas envolvidas em vários outros projetos: bandas; sites, fanzines, selos independentes voltados para o lançamento de CDs de bandas de mulheres, etc. O LadyFest ocorreu uma vez por ano no período em que estive em campo e, com exceção de 2007, era realizado em datas próximas ao 8 de março, Dia Internacional da Mulher. A cada edição era escolhido um tema em torno do qual se desenvolviam as atividades do festival. ${ }^{10} \mathrm{O}$ item da programação que reunia maior número de pessoas eram os shows.

A maior parte das bandas é composta exclusivamente por mulheres e, quando há homens na composição, eles não aparecem em posição de liderança. Ilustrativo disso, é que as garotas procuram deixar claro que, apesar da presença de um ou mais garotos na banda, não há dependência técnica ou criativa em relação a eles. Em uma das bandas, havia um garoto durante

${ }^{10}$ Em 2004, o tema foi "Conhecimento para a resistência feminista". Em 2005, o foco foi a violência: "NÃO à violência contra a mulher, NÃO ao silêncio e SIM nós somos feministas". Em 2006: "É MENINO OU MENINA? - Gênero: o machismo torturando nossa identidade". Em 2007 o foco foi a sexualidade, com o tema "Tire sua própria virgindade". 
"Não faz mal pensar que não se está só"

certo período, mas o rapaz criou um personagem feminino e se apresentava vestido de mulher. Esse mesmo rapaz publicava um fanzine no qual figuravam textos feministas de sua autoria. ${ }^{11}$ Embora abertos à presença de rapazes, os shows são majoritariamente frequentados por garotas, que também se encontram em casas de rock alternativas, em bares no estilo boteco e festas domésticas. São comuns as viagens para tocar em outras capitais brasileiras, e mesmo no interior do estado, onde a cena tem se fortalecido nos últimos anos. Para as bandas mais antigas ou conhecidas, há também a possibilidade de viagens para o exterior, para tocar e/ou para trocar experiências com garotas da cena em festivais ou workshops.

Numa cena constituída por garotas bastante jovens, de estratos médios e médio-altos, as ferramentas de comunicação na internet têm bastante importância. Além de projetos virtuais mais complexos e coletivos, como o Quitéria ${ }^{12}$, há vários blogs, comunidades no Orkut $e$, mais recentemente, fotologs que divulgam as informações sobre bandas, shows e oficinas. Ednie Kaeh Garrinson (2000) chama atenção para a importância do uso de "tecnologias democratizadas" para a formação de "redes", tanto no feminismo norte-americano de "Terceira Onda", quanto no movimento Riot Grrl, que situa em seu interior. Vale enfatizar também que tais tecnologias de informação tendem a servir muito

${ }^{11}$ Quando, num outro festival punk, o QueerFest, ele participou da apresentação da banda que havia integrado, tive a oportunidade de lhe perguntar porque tocava vestido de mulher, ele me respondeu que teve essa ideia por se tratar de "uma banda de meninas numa cena de meninas".

${ }^{12} \mathrm{O}$ site apresentava-se da seguinte maneira: "Quitéria é uma revista pop feminista online, para meninas interessadas em música, informação, arte e debate. Feminismo, além de ser uma luta por mudança social, produz uma quantidade de cultura imensa $e$ - porque não dizer? - divertida. Bandas, fanzines, livros, bate-papo em mesa de bar, tudo isso e mais um pouco, em mais de 10 anos consolidou uma cultura feminista jovem interessantíssima no Brasil. Digite riot grrrl+Brasil no Google e tenha certeza disso" [ www.quiteria.com.br acesso em 01/10/2006] 
bem às ideias de faça-você-mesmo e ao incentivo à autoexpressão das mulheres, característica da cena.

A pluralidade de projetos existentes tem relação com a incorporação de um dos elementos do estilo punk, o do-it-yourself ou faça-você-mesmo. Assim, as próprias garotas tocam os instrumentos, compõem, atuam como DJs, como técnicas de som, fotografam e filmam os shows e atividades da cena e os divulgam através de fanzines e sites na internet. O faça-você-mesmo é central ao feminismo das minas do rock e é compreendido de modo específico dentro dele:

O faça-você-mesmo, tipo, se você não fizer, ninguém vai fazer. Isso é a coisa central no riot grrrl. Você não perder seu tempo com os caras, se eles quiserem ouvir o que você tem a dizer, beleza. A ideia é você fortalecer as meninas, não é você convencer um menino de que ele tá errado, é você pegar e ensinar a menina a se defender. Esse é o preceito central do riot grrrl pra gente, isso eu levo pra vida inteira. Porque, o quê que aconteceu? Uma das grandes ferramentas da cultura mesmo, até pra barrar o feminismo, é esse papinho: "Não, vocês estão sendo contra homens, não sei o quê". E aí, tipo, a gente foi percebendo que isso tava entupindo o nosso canal de comunicação com as meninas. O cara vem me questionar, eu falo assim "Você quer aprender alguma coisa, você tá afim mesmo de entender alguma coisa ou você tá querendo me irritar?" O feminismo do riot grrrl é isso, e é muito agressivo, nesse sentido, pros homens, né? Ele é um tipo de feminismo que pega porque ele ignora os caras em alguns níveis. E é assim que a gente construiu a cena. (entrevista com Beatriz, 2007).

As temáticas exploradas nos projetos remetem ao feminismo presente na cena, que, além de pautado no faça-você-mesmo e numa atuação que valoriza a ação autônoma e tem as garotas como protagonistas, articula uma espécie de "fraternidade feminina", que tem nas relações afetivo-sexuais entre as jovens uma expressão bastante visível e valorizada. 
"Não faz mal pensar que não se está só"

Embora a cena das minas do rock não fosse pensada como um espaço relacionado à sexualidade ou à homossexualidade, as dykes se tornaram referência na cena. Essa era uma característica central no período em que estive em campo, tanto que não demorei muito a perceber a importância da categoria dyke e o fato de que tivesse vários sentidos, assim como fiquei intrigada pela valorização que havia em torno da temática e das relações homossexuais. A visibilidade das dykes ou do dyke rock na cena também é citada nas pesquisas de Erica Melo (2008) e de Michelle Alcântara Camargo (2010), embora esta última a situe como um traço específico do período em que estive em campo e da "geração" de garotas que eram então protagonistas dos projetos e bandas mais valorizados na cena.

\section{Dykes e sapatões na cena: questões de estilo e atitude}

No início, a cena era formada majoritariamente por garotas bastante jovens que se reconheciam como feministas, algumas explicitamente homossexuais. O questionamento a fontes de desigualdades sociais (como o machismo/sexismo, o racismo $e$, mais especificamente, a homofobia) é referência da cena riot grrrl em âmbito internacional. ${ }^{13}$ Apesar da homossexualidade não ser o foco principal da cena, os discursos anti-homofobia eram bastante comuns, indo desde um tom mais "sério" até versões mais irônicas.

Com o passar do tempo, ficar com outras garotas e não omitir essas relações passaram a ser atitudes muito valorizadas na

${ }^{13}$ Garrison (2000:155) relacionaria os temas encontrados nas músicas de bandas norte-americanas, como Bikini Kill, Bratmobile, Team Dresh, Heavens to Betsey, Sleater-Kinney: racismo, sexismo, abuso infantil, violência doméstica, sexualidade, classismo, privilégios, indústrias do sexo, espetacularização da mídia, Aids, apatia, girl power, questões ligadas ao consumo, elitismo na cena rock, mercadorização de um estilo descolado. Se não todos, boa parte desses temas estão no repertório das bandas paulistas. Outras pesquisadoras do tema em âmbito internacional (Rosenberg; Garofalo, 1998; Wald, 1998) também apontam para a tematização de várias fontes de opressão ou eixos de diferenciação social entre as riot grrrls. 
cena. Assim, as dykes ganharam visibilidade a ponto de se tornarem referência no rock de mina e de abrirem espaço para o reconhecimento de outras garotas que chegavam aos shows, como podemos perceber pelo tom de encantamento no relato a seguir, de uma entrevistada que teve o primeiro contato erótico com mulheres em um show das minas do rock:

Quando a gente começou a frequentar os shows de rock de mina, foi uma realização, assim, você ouvia elas falarem tudo aquilo que você não sabia pôr em palavras, sabe, assim? Era muito libertário pra gente. Por isso que eu te falei que parecia um mundo paralelo. Me chamava a atenção a facilidade com que elas falavam que eram gays e como falavam bonito do feminismo. Umas coisas que eu, como era mais nova, não sabia como falar pras pessoas, então só usava aquelas frases clichês. E elas falavam com muita naturalidade, não era decorado, era com sentimento. E aí você fica encantada, porque, imagina, você é mulher e sempre te trancaram num mundo e, de repente, você descobre outro, onde você pode ser você mesma. Isso que é muito legal do rock. Eu me descobri bastante, assim, como pessoa. (...) A primeira vez que eu fiquei com uma menina... Eu ia em show de banda feminista, Hangar e tal. Era uma coisa muito natural, minhas amigas ficavam com minas, era o Dominatrix, elas eram lésbicas. Rolava muito, na época, uma coisa de, tipo, beijar todo mundo, beijo a três. Então, foi meio isso, a gente ficava todo mundo meio que se beijando, aí tava eu e ela, a gente não se conhecia e a gente se beijou. (...) Então, quando eu comecei a ficar com menina, era natural, eu estava a fim de ficar com menina, então, vou ficar com menina (entrevista com Vera, 2007).

Nas entrevistas, a descrição acerca do lugar que dykes ocupam no cotidiano da cena, não apenas demonstra a valorização do "ser dyke", como aponta para o fato de que, embora dyke apareça como o oposto de heterossexual, o uso, 
"Não faz mal pensar que não se está só"

tanto da categoria dyke quanto da heterossexual, parece não pressupor uma correlação necessária entre práticas afetivo-sexuais $e$ identidades. Assim, heterossexual não exclui eventualmente beijar meninas ou gostar da companhia feminina e da diversão compartilhada entre mulheres nas festas e shows. A mesma separação entre identidades e práticas está presente nas eventuais queixas de algumas dykes quanto ao fato de que muitas garotas hetero se aproximem delas na balada só para experimentar ou por curiosidade. Ter experiências sexuais com mulheres não faz de alguém uma dyke, nem faz com que quem experimenta ou mesmo tem relações casuais com outra mulher deixe de ser considerada hetero. Isso parece ganhar lugar num contexto no qual outros estilos jovens marcados pela presença de estratos médios, como é o caso dos modernos ${ }^{14}$, valorizam e têm a experimentação sexual com o mesmo sexo como algo inclusive esperado nos espaços de lazer noturno.

Ainda que deslocada de uma relação de continuidade entre desejo, prática e identidade, o uso da categoria dyke remete a uma estratégia de inversão do sentido de termos estigmatizados. Isso explica porque, em dado momento, algumas garotas começaram a se referir a si mesmas, e às outras, como sapatão, transferindo ao termo, todo o sentido cool que ser dyke na cena riot grrrl tomou nos últimos anos:

A gente chama de dyke qualquer sapatão. Mas o dyke, na verdade, foi criado, porque dyke, em inglês, é tipo um xingamento, é tipo um homem virar pra você e falar "sua sapatão, sua nojenta". E as minas do rock de lá, dos EUA, que nem a gente, começou a usar o sapatão, porque antigamente a gente não usava sapatão, os caras chamarem de sapatão era agressivo, hoje em dia a gente chama uma a outra de sapatão e é normal. Tem gente que acha até menos ofensivo que lésbica. Mas, aí, o dyke

${ }^{14}$ Sobre a cena moderna em São Paulo ver França, 2007, Vega, 2007 e Facchini, 2008. 
Regina Facchini

começou a ser usado por elas mesmas pra chamar as meninas do rock lésbicas (entrevista com Tatiana, 2007).

Letras de música, como as do Projeto Santa Claus, uma das poucas bandas que compunha em português, apontam claramente o sentido dessa estratégia na cena: os versos abaixo são cantados sobre uma base de música eletrônica, acompanhada por guitarra, para uma platéia lotada de garotas, em plena celebração pública e coletiva do "ser sapatão":

você me olha

como se eu fosse..

sapatão.

sapatão?

sapatão!

eu sou sapatão

eu sou sapatão

eu sou sapatão

e daí?? (Eu sou sapatão!, Projeto Santa Claus)

Para além da referência à sexualidade, dyke parece, por vezes, ser usada de modo intercambiável em relação aos termos que nomeiam a própria cena do rock de mina: mina do rock ou riot grrrl, se espalhando com a influência que o feminismo do rock e sua cena cultural foram adquirindo. Esse uso delimita outras condições para que uma garota seja entendida como uma dyke, $e$ elas dizem respeito ao estilo:

É um visu, um comportamento e um estilo de música. Dyke é electro, rock, roqueira que curte eletrônico e que usa calça apertada, All Star, um cabelo curto, meio punk, assim, mas também meio electro mesmo, né, que é a tendência, que é a cultura jovem hoje em dia. Então, a dyke tem um lado de emo também, piercing e tal... Também tem a coisa do estereótipo do rock, tipo ser uma pessoa louca, bêbada, que tipo, se acaba, usa droga... E só que ela sabe o que é feminismo, entendeu? (entrevista com Beatriz, 2007) 
"Não faz mal pensar que não se está só"

As dykes se tornaram ícones de um feminismo jovem baseado em estratégias culturais que ousam conjugar no feminino atividades como fazer rock e dominar tecnologias, tradicionalmente mais restritas ao masculino. Já o uso do termo sapatão é uma estratégia tida como mais radical de desestabilização da categoria de acusação mais poderosa lançada contra mulheres que se relacionam afetivo-sexualmente com outras mulheres.

Ao evocar um insulto simbolicamente tão poderoso, essa última estratégia gera situações de estranhamento, sobretudo quando utilizada em presença de um grupo mais diversificado de mulheres, como quando, na VI Caminhada de Mulheres Lésbicas e Bissexuais de São Paulo, uma garota de visual que remetia às minas do rock gritou "Â̂, sapatão!" no microfone, gerando olhares desconfiados e assustados das outras mulheres.

Essa situação aponta para a radicalidade da estratégia num contexto em que não só lésbica ainda é considerada uma palavra pejorativa e é pouco usada fora de meios ativistas, como boa parte das mulheres de extratos baixos e médios-baixos se qualificam como entendidas ou homossexuais, primando pela discrição (Facchini, 2008 e 2009). Nesse sentido, o uso de sapatão na cena do rock de mina talvez fale menos do estilo em si mesmo do que de uma estratégia política típica da atitude e do ideário político que perfaz o estilo e em torno do qual se constitui a cena.

\section{“Faça você mesma!": um feminismo do rock}

Como vimos anteriormente, a versão de feminismo presente entre as minas do rock mistura elementos de certa "fraternidade feminina", que se estendem a comportamentos homoeróticos entre as dykes, com muita ênfase no empoderamento e no fortalecimento do protagonismo ${ }^{15}$ e capacidade de expressão das

${ }^{15}$ Pode parecer curioso o uso, numa cena punk, de termos que pertencem ao vocabulário de agências internacionais de fomento a ações de combate às "desigualdades de gênero". Numa consulta a textos acadêmicos sobre riot grrrls 
mulheres. Essa versão de feminismo é compartilhada por toda a cena riot grrrl em âmbito internacional, responsável por boa parte das viagens e do intercâmbio internacional.

O tema da violência é um dos mais abordados na cena. Embora haja toda uma ênfase na polarização entre homens $e$ mulheres $e$ no confronto a atitudes cerceadoras $e$ violentas praticadas por homens contra mulheres, há atividades que mostram uma abordagem bastante complexa $e$ inovadora do tema da violência. Além de enfrentarem questões difíceis e pouco tocadas, como a violência/abuso sexual contra garotas no núcleo familiar, o tema da violência no âmbito das relações afetivosexuais é abordado de modo criativo.

O site Quitéria, referência na cena, além de manter um acervo de relatos de mulheres vitimadas por violência/abuso sexual (o acervo do BenditaZine ${ }^{16}$ ), também contou, entre suas organizadoras, com as responsáveis por um trabalho de intervenção com relação à violência no interior de relações homoafetivas entre mulheres. Essas intervenções, no formato de oficinas, tomavam por base a noção de consenso sexual e, apesar de ser um trabalho inicialmente focado na própria cena, e que se expandiu apenas a partir das redes relacionadas a ela, foi o trabalho mais consistente e de maior alcance em relação ao tema

em âmbito internacional, encontrei essas mesmas referências. O mais provável, tomando em conta o fato de que as minas do rock não são muito afeitas ao feminismo mais institucionalizado, é que os termos tenham entrado em seu vocabulário via cena internacional. Para um panorama do pensamento das riot grrrls, nos EUA, ao final dos anos 1990, ver o texto Riot Grrrls: revolutions from within (Rosenberg; Garofalo, 1998).

${ }^{16}$ Iniciado como um fanzine de papel, em sua versão eletrônica o BenditaZine também era dedicado a romper o silêncio em torno da violência contra mulheres. Publicava, na íntegra, depoimentos de mulheres que haviam sofrido qualquer tipo de violência, mantendo seu anonimato e era um espaço bastante usado por garotas que relatavam abuso sexual na infância. Esteve hospedado desde o lançamento do site até meados de 2007 no site Quitéria. 
"Não faz mal pensar que não se está só"

que já pude observar no cenário dos movimentos sociais brasileiros. ${ }^{17}$

A metodologia das oficinas Consenso sexual para jovens lésbicas lembrava um pouco dinâmicas de grupo, em que eram apresentadas situações em torno das quais cada subgrupo deveria se posicionar e depois debater coletivamente. Isso fazia com que, a cada vez que era realizada, novos elementos fossem sendo agregados à reflexão, compondo um acúmulo de discussão que já seria ponto de partida para a próxima oficina. Um dos principais focos da oficina estava na ênfase colocada na capacidade de dizer e de respeitar um "não". Contudo, as oficinas não eram uma estratégia isolada do restante das atividades da cena. $\mathrm{O}$ mesmo ocorria com oficinas como "Wen-do, auto-defesa para mulheres" ou "ginecologia do-it-yourself", que foram oferecidas como parte integrante das edições do LadyFest. No caso da capacidade de dizer e de aceitar um "não", a mensagem é reforçada inclusive em letras de músicas:

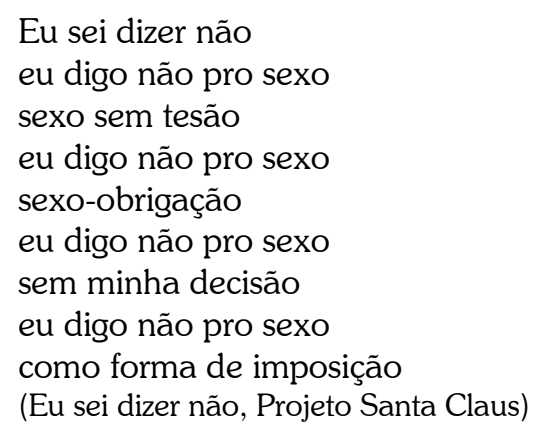

${ }^{17}$ Reforço a consistência e o alcance desse trabalho pontual, porque a tematização da violência em relações afetivo-sexuais entre mulheres é algo que vi ser tratado apenas esporadicamente em oficinas nos Senale (Seminário Nacional de Lésbicas) e em uma ou outra mesa de debates organizada pelo ativismo lésbico em ocasiões especiais. Apesar das situações conflituosas e mesmo violentas serem muito frequentes em bares e boates e dos desfechos violentos dos "casos" serem bem conhecidos e até motivos de piadas, desconheço alguma iniciativa que não seja meramente pontual no movimento lésbico ou LGBT, que tenha se dedicado mais especificamente a isso no Brasil. 
Embora a cena das minas do rock não possa ser confundida com o movimento anarco-punk ou com a cena straight edge, que também possuem muitas iniciativas no campo do combate ao racismo, ao sexismo e à homofobia, boa parte das iniciativas na cena riot grrrl nos remete aos princípios do faça-você-mesmo e/ou da ação direta, caras ao punk e a posicionamentos políticos anarquistas. Embora haja pontos de diferenciação entre tais práticas políticas e culturais, é possível perceber um campo mais geral de referências políticas compartilhadas. Trata-se de um campo um tanto difuso, mas fundamental para entender melhor as relações que se estabelecem entre as riot grrrls e o movimento feminista mais amplo.

Entre 2004 e 2006 acompanhei um pouco mais de perto por meio da participação em listas de discussão, encontros nacionais e internacionais, marchas, atos e outras atividades do movimento - a busca de inserção das riot grrrls no cenário do movimento feminista, em âmbito nacional. Não raro, porém, as riot grrrls se ressentiam do que interpretavam como preconceito ao seu estilo de feminismo e ao formato de sua atuação cultural, o que era traduzido como preconceito com relação às minas do rock. Ao que respondiam, eventualmente, com críticas à dificuldade do movimento em renovar seus quadros e atrair um público jovem, em contraste com a grande adesão que as estratégias de atuação das minas do rock, baseadas no lúdico e no cultural e no diálogo direto e prático com as questões cotidianas, conseguem ter entre as garotas mais jovens. Nesses momentos, se estabelecia uma distinção entre o feminismo das minas do rock $e$ o que aparecia como feminismo institucional, tradicional ou do pessoal de ONG:

Acho que a grande diferença é uma coisa muita ligada à estética, o feminismo das jovens do rock também está ligado a uma maneira de se vestir, a uma música que você escuta e não é muito profundo intelectualmente, assim, 
"Não faz mal pensar que não se está só"

com pouca informação. São poucas as meninas que, de fato, vão atrás de coisas. A maioria pega como uma doutrina de vida por já ter desconfiado que estava alguma coisa errada e se identifica com isso: "Eu sou feminista, porque eu acho errado os caras serem toscos comigo $e$ machistas" ou "Eu sou feminista, sim, porque eu acredito que as mulheres precisam ter mais direitos...". Uma coisa bem básica. No feminismo do pessoal de ONG ou que vai a congresso, a galera leu mais livro. As Jovens Feministas, por exemplo, quando eu encontro com elas, o papo vai um pouco mais longe do que quando eu encontro com as meninas de banda, eu consigo aprofundar um pouco mais. Só que, em alguns momentos, no feminismo da cena, a discussão que as meninas têm em termos de sexualidade tá um pouco mais aprofundada. Existe mais transgressão de gênero, esteticamente, acontecendo no feminismo roqueiro. Elas estão brincando e, até meio intuitivamente, elas estão colocando em prática um feminismo até mais profundo do que o tradicional. A menina estar vestida de homem cantando no palco, e aí tira a roupa, fica com roupa de mulher e fala: "Ah, eu vou fazer o que eu quiser"... Pra quem olha tem um impacto de ter um feminismo transgressor. Isso eu não vou ver num congresso. Não é profundo intelectualmente, ela não falou um discurso mega elaborado de gênero, só que aquilo tem um impacto que é muito interessante pras meninas que estão vendo. No rock feminista, as meninas falam: "Ah, vou te comer" ou "dei pra fulana". Então, não têm muitos pudores em usar esses termos que normalmente levam a discussões sobre o sexo lésbico ser horizontal... Elas se apropriam dos termos, têm menos medo de linguagem $e$ acho que rola uma apropriação boa, sabe, de termos que são considerados tradicionalmente machistas e que elas acabam tirando o poder desses termos. E aí tem essa diferença. Aí, que eu vejo que a gente tem uma coisa estética importante, a gente tem mais prática com carisma, a gente domina a linguagem mais que elas, a gente mobiliza melhor, é mais generosa com informação, a gente lidera melhor, entendeu? Elas 
conseguem grana, a gente não consegue trabalhar com coisas de governo, mas a gente consegue juntar mil meninas num festival (entrevista com Beatriz, 2007).

O foco nas transgressões estéticas é bastante significativo na cena e, olhar mais atentamente para essas transgressões, permite entrever um feminismo que, longe de ser unitário, seria melhor descrito como polifônico, revelando um conjunto diversificado de vozes e subjetividades. ${ }^{18}$

\section{Transgressões estéticas: operando diferenças}

Tomar como foco a análise de tais transgressões é o mote para pensar o sentido da diversidade interna do estilo na cena riot grrrl paulistana, bem como o lugar que tal estratégia ocupa em relação aos processos de produção de subjetividades entre as garotas da cena. Ao definir o sentido em que a noção de estilo seria usada em minha tese de doutorado (Facchini, 2008), argumentei em favor de levar em conta o caráter "espetacular" do estilo como forma de "dar-se a ver" (Abramo, 1994) e comunicarse, bem como de considerar as múltiplas relações de poder nas quais se inscreve o que é comunicado, abrindo espaço para pensar estilos como operadores de diferenças. Referi-me ainda à necessidade de situar os estilos a partir de uma concepção de sujeito que permita pensá-lo em sua dimensão processual (Brah, 2006), considerando que sujeitos são constituídos no processo em que elaboram e se expressam por meio de um estilo.

\footnotetext{
${ }^{18}$ Além da diversidade interna, deve-se levar em conta o dinamismo da cena novas bandas e projetos surgem constantemente com a entrada de novas garotas ou mesmo a partir da reformulação de projetos já existentes. Desse modo, a análise aqui empreendida capta estilizações, projetos e questões que estiveram presentes num dado momento na cena paulistana. Passados alguns meses entre meus últimos contatos em campo e o momento em que escrevo, é preciso destacar que possivelmente existam outras bandas, projetos, questões e relações no interior da cena.
} 
"Não faz mal pensar que não se está só"

Retomo esses argumentos mais adiante. No entanto, gostaria, anteriormente, de apresentar uma série de imagens e de cenas que permitem dialogar acerca deles:

Cena 1: LadyFest Brasil 2006, Hangar 110, show do Cínica. Uma pin-up gordinha, sexy e tatuada entra em palco de saia curta rodada, camiseta regata preta e de meia arrastão. No meio da primeira música, levanta e depois despe a saia e continua rebolando com uma calcinha preta de bolinhas brancas sobreposta à meia e brinca com um boá verdechamativo, virando o rosto de modo a jogar os cabelos de tamanho médio, pretos e desfiados de um lado pro outro. Seu visual e sua performance, marcadamente sensual, pareciam deslocadas do cenário do show, contrastando com o local, a platéia e com o estilo mais andrógino das outras garotas de sua banda (Diário de campo, março de 2006).

Cena 2: LadyFest Brasil 2007, Inferno Club.

Sobe ao palco a vocalista da banda The Dealers, descrita, numa resenha do show na mídia especializada, como alguém que reúne qualidades como ter personalidade, carisma, competência e ser dona de um vocal energético e simpático. Mesmo após constatar problemas no som, ela não se exaltou, dialogava com a platéia, sugerindo que as pessoas se divertissem e bebessem. Enquanto isso, ajustes no som eram rapidamente feitos para possibilitar a continuidade do show. Assim que subiu ao palco, um amigo que me acompanhava havia me chamado para elogiar a beleza do "garoto". "Como assim, garoto?" - digo rindo - "essa é a XXXXX, que também toca no Dominatrix e no Biggs!" Magra e com uns vinte e poucos anos, usava calças masculinas justas de cintura baixa, camiseta branca sem mangas, justa, curta e meio batida, sobreposta a outra de cor preta e tênis All Star de cano alto de um branco-sujo. Piercing no lábio inferior $e$ alargadores nas orelhas, tatuagem no braço, axilas peludas e um topete enorme no estilo rockabilly. Dona de um estilo rock star meio junkie, 
Regina Facchini

tinha uma performance invejável no palco: movia-se o tempo todo, brincava com a platéia, jogava-se ao chão ou subia na bateria, usando até uma levantada estratégica da blusa no momento certo, permitindo ver parte dos seios (que, em outras ocasiões, notei estarem cobertos por faixas que os invisibilizavam) (Diário de campo, outubro de 2007).

Cena 3: LadyFest Brasil 2006, tema "Menino ou menina? O machismo torturando nossa identidade".

A vocalista, guitarrista e programadora de bases do Projeto Santa Claus sobe ao palco de calças largas, camisetão $e$ coturno. Seus cabelos são curtos e apenas o rosto permitia perceber no conjunto da apresentação que se tratava de uma garota. Tocou vestida desse modo uma parte do show. Num dado momento, ela tira a camiseta e a calça no palco $e$ percebe-se que, por baixo dessa roupa, trazia um vestido preto decotado e curto e meia arrastão. O coturno deu lugar a um sapato de saltos altos e uma maquiagem rápida foi feita. Após a transformação, os coturnos no canto do palco, ela fala algumas coisas sobre as restrições colocadas pelas noções de masculino e feminino e diz: "Eu vou fazer o que eu quiser!" (diário de campo, março de 2006).

Cena 4: LadyFest Brasil 2007, show de encerramento no Outs ${ }^{19}$, resenha do site Banana Mecânica. ${ }^{20}$

Luzes baixas, quatro meninas entram no palco. Posicionam-se lado a lado, de costas, lá no meio. A música começa, com direito a clipe no telão. Elas se viram. Playbackão na veia. "Abro um vinho / mas não tenho / um porquê para brindar / A sua taça continua vazia", entoa uma das vocalistas, Kerby.

Dykes 4ever é a primeira "boyband" assumidamente dyke. Todos os estereótipos dos fenômenos pop masculinos da

${ }^{19}$ Você para mim - Dykes 4ever - Lady festival 2007 [http://www.youtube. com/watch?v=euVGZSdy8uc\&NR=1 - acesso em 25/03/2011].

${ }^{20} \mathrm{Schmidt}$, Fernanda. Dykes 4ever [http://www.bananamecanica. com.br/ conteudo/index.php?op $=$ ViewArticle\&articleId $=816 \&$ blogld $=3$ - acesso em 23/10/2007]. 
"Não faz mal pensar que não se está só"

década passada estão lá: a étnica, a bela, a romântica e a whigga. Estrofes açucaradas e muita pose.

Piada interna, externa? Extrapolada! É inevitável não se empolgar com a apresentação do quarteto. Muitas risadas do público, passos ensaiadinhos do grupo. A letra é digna de qualquer hit nacional, como 40 Graus ("A cada dia, a cada vez / Que eu te vejo, ali no play, / Eu fico tonto, eu fico mal"), do saudoso Twister.

O início do Dykes 4ever é um mistério. A banda surgiu "da terra onde os sonhos nascem", afirmou Kerby, que divide vocais com Toby, Joey $\mathrm{C}$ e Maria José. O repertório do grupo é composto apenas pela canção apresentada no Ladyfest, Você para mim, escrita por Joey $\mathrm{C}$ e que teve clipe veiculado na MTV.

O encerramento do festival foi rápido. Durante os três minutos e pouco da música, braços estavam para o alto, com algumas fãs pedindo a atenção de sua integrante favorita e acompanhando parte do refrão-chiclete. Ao fim, as quatro receberam os aplausos juntinhas em pose postada na beira do palco. Nada mais pop.

Olhar para essas cenas, em seu conjunto, remete a um diálogo com referências musicais e estilísticas do mundo do rock e mesmo do malfadado pop. Assim, vocalistas pin-ups, rock stars junkies, rappers, garotos de boybands, garotas maquiadas e de saltos com suas guitarras desfilam pelos palcos do LadyFest. Ao mesmo tempo em que fazem e desfazem estilos, com uma leveza que dá um tom lúdico e deixa evidente uma intencionalidade de brincar, citando ou ironizando referências, elas parecem também fazer e deslocar gênero.

Se o rock é um estilo musical que, durante muito tempo, foi predominantemente conjugado no masculino, o que acontece quando garotas tomam o palco e colocam em cena diferentes feminilidades e masculinidades? E quando um rock star carismático e junkie habita o corpo de uma garota que mostra os seios no palco ou uma boyband é composta por garotas e tem seu 
vídeo veiculado na $\mathrm{MTV}^{21}$ ? Que marcadores de diferenças são acionados? Que relações de poder são tensionadas nessas performances e num estilo que as exibe lado a lado? Vejamos mais uma cena:

Cena 5: Numa comunidade do Orkut, discute-se o vídeo e o show do Dykes 4ever:

Garota 1 posta: Que conjunto ruim da porra!!!! É sério!!! Não é pelo fato de sermos lésbicas q temos q ser tapadas e não perceber quando a música $e$ as cantoras dessa turma ai ser um lixo! Porra! Como desafinam!! E a música??!!! Cafonerrima! Fora de tom!!! Letras imbecis!!! Gente !!! E akela integrante q é uma caricatura de rapper??!!!! Gesticulando igual aos negrões americanos! Ridícula! Quer imitar um homem, façam como eu: imitem um metreossexual como David Beckham, ao invés de pegar o pior modelo (rappers, Waldick Soriano, Agnaldo Timóteo, Jece Valadão, Reginaldo Rossi, os caminhoneiros, enfim, esse tipo de homem desengonçado e desprovovido de sensualidade e q nehuma mulher mais tá afim!)! Vams lutar pra classe lésbica ser melhor representada, gente!!! Ai, Brasil, quando irás pra frente???? [sic]

[...]

Garota 2 (que também é integrante da banda, embora com codinome) posta: HAHAHAHAHA elas são minhas amigas? acho que a tapada aqui é vc. o mais legal é que vc pensa que isso é de verdade. querida, não consegue entender uma piada? da onde vc surgiu?

Garota 3 (amiga e parceira em outra banda da garota 2 e de outras integrantes do Dykes 4ever) posta: Opa David, e aí bele? Olha, peguei pra mim oq vc deixou no orkut das minhas amigas, não por querer defender ninguém, pq se fosse defender alguém teria que ser você, mas por achar que você não està percebendo o quão toska $e$ PRECONCEITUOSA está sendo. O que você chama de

${ }^{21}$ Dykes 4Ever. [http://www.youtube.com/watch?v=OQrC4jNM7To - acesso em 25/03/2011]. 
"Não faz mal pensar que não se está só"

"classe lésbica"? oq vc está tentando provar, e para quem? Não é por que somos lésbicas, gays, travestis, oq for, que temos que seguir um modelinho estipulado/sistematizado não. E viu, críticas são sempre muito importantes quando a pessoa na qual as estão colocando sabe do que está falando, senão vira uma piadinha sem gra-ça. Só mais uma coisa, pq você acha que David Beckham é melhor do que qualquer 'negão americano',como vc colocou? Por ele ser branquinho, se fazer de bonzinho pra mídia? Isso achei bizarro. Uma pessoa que sofre preconceito, tão preconceituosa.. É uma pena. Enfim, estão aí nossas diferenças e os porques de eu e minhas amigas não sermos da mesma 'classe' que você, e sendo tão GAYS quanto heim. Se encontra gata. Bota essa sua energia, essa sua atitude e vontade de falar, em algo construtivo. Falou.

Uma das divergências entre as garotas que argumentam depois, e a primeira, diz respeito à ideia de imitação: o que elas fazem não é uma imitação. Embora elas não usem essa palavra, tratava-se de uma paródia. Talvez, algo mais próximo de minas do rock rindo de garotos, expondo o caráter construído de suas masculinidades, do equívoco de serem tomadas como "naturais", por oposição à "artificialidade" das feminilidades e do pop, tudo ao mesmo tempo e, de quebra, reafirmando a ideia de que podem fazer o que quiserem.

A segunda divergência: ela não entendeu, era uma piada. Claro que seria mais fácil entender se a garota 1 pertencesse à cena e soubesse que as integrantes da boyband têm suas próprias bandas, que não são pop, que não cantam mal e não fazem letras imbecis. A banda era uma piada interna e a cena riot grrrl não é mesmo muito permeável: como um estilo, tem de estabelecer critérios que delimitem seus contornos. A iniciativa ou atitude é plenamente valorizada na cena, mas o fato de ser "mulher" ou "lésbica" não faz com que alguém se torne "de dentro".

Isso leva a um terceiro ponto de divergência: haver ou não uma classe lésbica. Seguir um modelinho estipulado e ser 
Regina Facchini

preconceituosa quanto aos estilos de masculinidade ou à questão racial foram comportamentos delimitados como o motivo da diferença, que faria ser tão gay quanto, sem ser da mesma classe.

É necessário reconhecer a inventividade das transgressões estéticas e o modo como o feminismo das minas do rock subverte tanto a onipresença do tema violência na cena punk quanto o sentido do termo usado para agredi-las, bem como a contestação aos preconceitos, que está presente em suas atitudes e discursos. Para além disso, no entanto, é preciso lembrar que há um lugar do qual elas falam e que ele está intimamente ligado ao modo como o estilo é produzido.

Falamos de sujeitos situados em determinada posição nas relações de poder que envolvem classe, geração, cor/"raça", gênero e sexualidade. As minas do rock com quem interagi em campo para esta pesquisa poderiam ser descritas como mulheres jovens de estratos médios ou médio-altos e a maior parte delas é "branca" ${ }^{22}$ As menos jovens entre elas já concluíram seus cursos universitários: conheci algumas sociólogas, uma filósofa, uma

${ }^{22}$ Quando me afastava do campo para a escrita da tese, no segundo semestre de 2007, identifiquei a inserção das primeiras garotas "pretas" ou "pardas" na composição de duas bandas importantes na cena: Dominatrix e help! i'm a bonsai kitten. Já as "amarelas"/“descendentes de orientais" estavam presentes também em pequena quantidade desde que entrei em campo. A entrada de garotas "pretas" ou "pardas" em bandas não se fez sem problemas: o fotolog de uma das bandas relatava brincadeiras jocosas vindas da platéia de um show na Verdurada com a nova integrante da banda. Atitudes racistas, sexistas ou homofóbicas não coincidem com o ideário mais geral do coletivo Verdurada, mas o acontecido é significativo. Isso ocorreu já em 2008, e não foi possível, dado meu relativo afastamento do campo, investigar melhor, as implicações da recente visibilidade dessas garotas no interior das bandas. As então novas integrantes de bandas que poderiam ser classificadas como "pretas" ou "pardas" se vestiam como outras garotas da cena e mantinham seus cabelos crespos num tamanho médio, sem alisamentos ou tinturas. Até onde pude acompanhar a cena, não havia nenhuma vocalista "preta" ou "parda". Por outro lado, várias mulheres negras feministas estavam engajadas em blocos afro, como o Ilú-Obáde-Min, ou no movimento hip hop, em espaços como o Hip Hop Mulher. 
"Não faz mal pensar que não se está só"

linguista, uma veterinária, psicólogas, mas a maior parte atua na área de comunicação social ou produção cultural.

Isso remete à reflexão sobre as condições de acesso à agência social e cultural levada a cabo na análise comparativa que Gayle Wald faz do material relacionado a bandas de garotas norte-americanas e japonesas. A autora analisa como as

transgressões de gênero dentro das culturas musicais do rock contemporâneo geralmente se defrontam com codificações e recodificações menos transgressivas das identidades racializadas e nacionalizadas (Wald, 1998:589).

Majoritariamente situadas a partir de categorias não marcadas de classe e "raça", contando com ambientes familiares que aparentaram ser mais compreensivos em relação à (homo)sexualidade do que aqueles experimentados por outras entrevistadas para minha tese, o drama encenado pelas dykes parece ser a necessidade de encontrar um lugar mais confortável em relação a normatividades que estabelecem relações problemáticas entre mulheres, homossexualidade e feminilidade. Participar de uma cena em que a agência de mulheres jovens é questão central e em que há constantes questionamentos acerca do lugar que as garotas podem ocupar, oferece um campo propício para encenar o que chamo aqui de "drama dyke".

\section{Estilo, produção de sujeitos e agência social}

Para concluir este artigo, gostaria de olhar mais detidamente para o que chamei de "drama dyke", remetendo a uma discussão sobre estilos, agência, interseccionalidades e marcadores sociais de diferença. $\mathrm{O}$ faço com o intuito de procurar elaborar uma abordagem que possa sintetizar algumas das questões levantadas no decorrer deste artigo e que permita compreender a atuação das minas do rock como jovens feministas a partir do conjunto de posições de sujeito que informam tal atuação. 
Falar num drama encenado evoca a ideia de que estilos são "meios expressivos para negociar espaços e sentidos no campo da luta cultural" (Abramo, 1994:37) e de que se trata do uso de roupas, música e atitudes para "dar-se a ver" no espaço público. Desse modo, o estilo aparece como "forma de comunicação" $e$ como "encenação" e os projetos, as bandas e a própria cena poderiam ser tomados como "espaço de sociabilidade $e$ elaboração de uma identidade relativa à sua condição juvenil $e$ aos problemas nela encontrados" (id.ib.:159).

Gostaria, no entanto, de retomar essa circunscrição do estilo a uma "condição juvenil", a partir de uma perspectiva pautada pelas interseccionalidades (Brah, 2006), mesmo porque creio que as próprias descrições de Helena Abramo sobre esses jovens $e$ suas questões a ultrapassam. Pesquisas recentes indicam que a própria "condição juvenil" é, muitas vezes, percebida como atravessada ou mesmo constituída pela diversidade de condições e lugares sociais, a partir dos quais se vive a juventude (Abramo; Facchini, 2008). Para tanto, recorro ao estudo de Dick Hebdige (1979) sobre o significado do estilo em "subculturas juvenis": o autor compreende "subcultura" como indicativo de uma "cultura subalterna" ou modo de lidar com a "subalternidade". Hebdige inova ao se contrapor à ideia de "subalternidade" tomada a partir da oposição geracional, e ao partir para a análise de cada estilo em relação a um contexto que envolve não só os jovens e seus pais, mas o fato de pertencerem a uma classe de trabalhadores $e$ compartilharem a vizinhança com imigrantes, boa parte vindos de antigas colônias britânicas e vistos como "não-brancos":

Não tenho tentado prover uma explicação sistemática do "problema" do desvio, nem olhar em detalhes para os vários agentes do controle social (a polícia, a escola, etc.) que desempenham um papel crucial na determinação da subcultura. Por outro lado, tenho tentado evitar a tentação de retratar a subcultura (como alguns autores influenciados por Marcuse já se sentiram tentados a fazer) como repositório da "Verdade", localizar nas suas formas algum 
"Não faz mal pensar que não se está só"

potencial revolucionário obscuro. Mais do que isso, tenho apontado, nas palavras de Sartre, para o reconhecimento do direito da classe subordinada (os jovens, os negros, a classe trabalhadora) de "fazer alguma coisa do que é feito deles" - embelezar, decorar, parodiar e sempre que possível reconhecer e superar uma posição subordinada que nunca foi da sua escolha (Hebdige, 1979:138 - tradução livre).

Apesar de tomar a noção de "subcultura" como ponto de partida, Hebdige o faz de modo muito pouco convencional. Em seu trabalho, a "cultura subalterna" não é olhada de modo isolado, como entidade, mas como relativa a uma posição num campo de relações de poder. Posição que é dinâmica, assim como são dinâmicas as relações entre estilos, gerações e grupos raciais $e$ de classe enfocados.

A fim de escapar à tentação ou ao risco de substantivar relações (Strathern, 1996), ao invés de falar em "grupos subalternos" (negros, trabalhadores, jovens etc.), prefiro me referir a marcadores sociais de diferença ou eixos de diferenciação social e a relações de poder (Brah, 2006).

Gostaria de argumentar, ainda, que os estilos não são produzidos por sujeitos pré-dados que agem de forma inteiramente consciente em relação aos efeitos a serem provocados pelas mensagens comunicadas por dada composição de aparência, atitude e música, mas que os sujeitos são constituídos no processo de citar e deslocar normas sociais, e isso pode se dar no processo de composição ou de encenação de determinado(s) drama(s) por meio do estilo (Brah, 2006; Butler, 1998; 2002 e 2003).

Para retomar o "drama dyke" e o lugar que ocupa/ou na cena e aprofundar a reflexão sobre a produção de estilos, convido a pensar num processo de construção da subjetividade que se dá por meio do estilo e das relações entre objetos, roupas, cortes de cabelos, gestualidades, práticas eróticas, e que opera convenções sobre "masculinidade" e "feminilidade", bem como sobre cor/"raça", classe, sexualidade e geração. 
Entre as dykes entrevistadas, o estilo em processo permite entrever subjetividades também em processo (Brah, 2006). Um sentimento de "ser diferente" em relação a outras garotas com as quais conviveram fora da cena é constantemente invocado. Embora imagens relacionadas a uma "fraternidade feminina" sejam constantemente evocadas, elas parecem não acreditar numa concepção simples de igualdade, como indica o breve debate descrito no item anterior acerca da performance em tom de paródia da banda Dykes 4ever.

A cena, o grupo de amigas com as quais compartilham as atividades das bandas, constroem seus projetos ou apenas vão ao boteco ou à balada, funcionam como espaço para um processo constante de produção do estilo, mas também de produção de si mesmas como sujeitos viáveis. A busca pela possibilidade de agência num contexto que percebem, por diversos motivos, como hostil é o que as une. Lembrando Hebdige (1979), elas de fato procuram fazer algo - e o fazem coletivamente - daquilo que, de algum modo, foi feito ou lhes parece ter sido feito delas:

Beatriz: Eu demorei muito tempo pra começar a me construir esteticamente. Eu não sabia muito me aceitar. Isso teve um impacto esteticamente. [...] Porque, quando você tem um contato midiático com pessoas que seus pais dizem que são lésbicas, geralmente são pessoas masculinizadas... Eu ficava assim: "masculinizada não sou, feminina também não sou". E por falta de uma referência diferente, de um modelo diferente de mulher lésbica, foi difícil eu entender o que é que eu tinha que fazer comigo. [...] O que me incomodava quando o pessoal falava "sapatão" era essa coisa de achar que eu ia ter que ser tratada que nem homem pra ser o que eu era. Então, me incomodava na minha descoberta de lésbica, quando eu olhava figuras femininas e mais masculinas, nessa questão, mesmo, assim, de violência também. Porque eu sofri muita violência doméstica. E aí, eu sempre me senti muito vulnerável fisicamente, assim. Sempre! Mas eu não acho que eu era masculina na infância porque eu era masculina. Eu era 
"Não faz mal pensar que não se está só"

masculina porque eu não sabia o que eu era! $\mathrm{E}$ eu não gostava de coisas femininas tipo boneca, não era porque eu era lésbica... Eu tinha agonia estética com coisas femininas... porque eu achava assim, até uma certa idade da infância, assim, eu achava que essa coisa de casar e ter filho era uma coisa obrigatória mesmo! Eu achava que minha vida tava chegando ao fim. Que o fim era quando eu ia perder a virgindade com um cara, ia ter filho e ficar grávida. Então, a minha vida era muito curta. [...] Aí, a coisa do feminino começou há uns dois anos atrás. [...] Só que um feminino que eu construo, entendeu? O cabelo, por exemplo, eu nunca mais vou cortar curto. E é muito louco, sabe, é emocionante, é tipo você sair do armário. Pela primeira vez na vida eu tenho alguma coisa estética em mim que eu tenho certeza que eu não quero mudar: é feminino e eu gosto, e sou eu. Então, eu achei o feminino em mim, legal. Esse ano, eu descobri uma postura que é uma postura que eu gosto. É um jeito de andar que é diferente, que é mais feminino também. Ele está quase chegando num ponto que eu fale: "Não, está bom", entendeu? [...] Eu já estou com 27 anos, e eu ainda não sei o que eu quero da minha vida, enquanto pessoa, isso causa um caos dentro de mim muito grande, né? Do mesmo jeito que eu sou construída já, socialmente construída, enquanto personalidade, esteticamente eu não sei, entendeu? Muito estranho. Aí eu fico um pouco me culpando, assim, sabe? As pessoas te falam, desde que eu nasci até hoje: "Você é tão bonita, você devia não sei o quê, você devia não sei o que lá"... E você põe um brinco e a resposta que você tem das pessoas não é a que você queria ter, sabe? Então acho que eu evitei muito usar elementos femininos por não querer que as pessoas interpretassem desse jeito idiota, entendeu? Porque é como se você tivesse compactuando. Eu não to compactuando! [...] Tem uma coisa política a partir do momento, por exemplo, quando, nessa minha viagem, que eu tô falando no palco, que sou patricinha, mesmo. Por que é mais uma coisa, eu fico falando isso porque eu uso o palco até como um divã, assim, mas é uma coisa psicológica, minha, pessoal, e uma coisa política 
também, tipo da diversidade e de me aceitar como uma lésbica diversa, sabe, que encerra em mim várias coisas que são diferentes e contraditórias e conviver com essa contradição, entendeu? (entrevista com Beatriz, 2007 - grifos meus)

O relato extenso e intenso de Beatriz remete a um "drama" que também permeia a fala de outras entrevistadas, algo como: "que tipo de mulher sou eu?". Situar esse questionamento como um drama, decorre de sua intensidade e de sua persistência: uma questão formulada e reformulada tantas vezes, olhada sob tantos ângulos, mobilizando um grande investimento emocional. Tudo isso se dá num contexto em que a invocação da homossexualidade abre espaço para uma ruptura em relação à coerência entre sexo, gênero e desejo, levando a pensar em mulheres masculinas ou femininas, mas também masculinas e femininas. Por outro lado, essa fala invoca um processo de construção da subjetividade que se dá por meio do estilo e das relações estabelecidas entre objetos, roupas, cortes de cabelos, gestualidades, práticas eróticas $e$ "masculinidade" $e$ "feminilidade".

Questões geracionais - Eu já tenho 27 anos e ainda não sei o que quero -, de gênero e sexualidade são problematizadas nessa fala, sem que deixem de estar sobre um pano de fundo em que classe e cor/"raça" são vividas a partir de um lugar nãomarcado. Entretanto, dizer que classe e cor/"raça" são experimentados a partir de um lugar não-marcado, não significa pensar que a "branquitude" e o pertencimento a extratos médios ou médio-altos não coloquem questões específicas para construção de um lugar no gênero.

As pressões para que se tornem mulheres de determinada cor/"raça" e classe, com um lugar específico em relações de poder, são intensas:

As pessoas te falam, desde que eu nasci até hoje: 'Você é tão bonita, você devia não sei o quê, você devia não sei o 
"Não faz mal pensar que não se está só"

que lá'... E você põe um brinco $e$ a resposta que você tem das pessoas não é a que você queria ter, [...] as pessoas [tendem a interpretar de um] jeito idiota.

Pressões desse tipo são compartilhadas por garotas que são interpeladas por gênero, ainda que não tenham práticas homoeróticas e/ou não se sintam homo ou bissexuais. Todas estão submetidas a pressões consideráveis para se tornarem mulheres viáveis e bem sucedidas de sua cor e classe, o que implica restrições no campo de gênero e de sexualidade.

No entanto, para além da homofobia - simbolicamente expressa por meio da veiculação exclusiva de imagens midiáticas marcadas por padrões estereotipados de gênero -, a construção da subjetividade de Beatriz e de outras garotas na cena está marcada por outras formas de violência que envolvem outros marcadores sociais de diferença. Beatriz relata também a violência intrafamiliar sofrida durante a infância, outras garotas relatam episódios de abuso sexual. Algumas garotas usam a expressão sobrevivente de violência para se referir a si mesmas. Essas formas de violência implicam relações sociais de poder relacionadas a gênero, a sexualidade, mas também a geração. Além disso, assumem contornos específicos a partir da posição que essas garotas e suas famílias ocupam nas relações de poder que envolvem classe e cor/"raça". O modo como tais situações são silenciadas e trabalhadas na cena, num sentido de prover um espaço para "reparação" (Das, 1999), não deixam de estar relacionadas ao lugar um tanto específico que essas garotas ocupam nas relações sociais de poder. Isso não quer dizer, é claro, que garotas de perfis diferentes não possam ser acessados, passem a fazer parte da cena ou lidem com a violência através de um outro estilo politizado.

O esforço criativo na direção de elaborar e superar tais relações e episódios e encontrar, enfim, um lugar confortável tem muito a dizer sobre a visibilidade e o impacto que as dykes exerceram nos últimos anos na cena riot grrrl paulistana: suas 
paródias e deslocamentos em relação a gênero (Butler, 2002) remetem a questões prementes para muitas garotas, inclusive para as que não se relacionam com garotas. O drama das dykes, nesse sentido, não deixa de dialogar com o drama de outras garotas na cena. Encenar esse drama coletivamente, por meio do estilo, é algo que permite se unirem num projeto feminista, e se perceberem a partir de relações de fraternidade, mesmo que o foco da construção da subjetividade e da agência seja enunciado, por vezes, como individual: "vou fazer o que eu quiser!".

O olhar empreendido neste artigo leva a pensar que os estilos, assim como as categorias de (auto)classificação, que em dados momentos podem ser enunciadas como identidades, funcionam como operadores de diferença. Dessa forma, estilos, classificações e identidades apontam tanto para possibilidades de agência - fazer algo do que foi feito dos sujeitos em questão quanto para processos de diferenciação. Tais processos podem se dar em relação a outras garotas que não compatilham o estilo $e$ não sejam generosas, como podem se dar em relação a outras feministas, especialmente em situações em que aquilo que ocupa um lugar muito caro não é levado em conta. Se música, shows, vídeos, fanzines, oficinas, discursos e transgressões estéticas podem ocupar, na cena aqui apresentada, o lugar que outrora foi ocupado pela palavra dita ou escrita em grupos de reflexão, jornais, manifestos e passeatas, talvez olhar para o que há de comum entre jovens e adultas, feministas de ONG, acadêmicas e as que usam estratégias pautadas na ação direta seja um caminho para reconhecer e fazer valer a riqueza e a força do feminismo na atualidade.

\section{Referências bibliográficas}

ABRAMO, Helena. Cenas Juvenis: punks e darks no espetáculo urbano. São Paulo, Editora Scritta, 1994.

ABRAMO, Helena W.; FACCHINI, Regina. Relatório Juventude e integração sul-americana: diálogos para construir uma democracia regional. 
"Não faz mal pensar que não se está só"

Informe dos grupos focais no Brasil. São Paulo, Pólis, 2008 [http://www.juventudesulamericanas.org.br/index.php/biblioteca/doc_ download/44-juventude-e-integracao-sulamericanadialogos-paraconstruir-uma-democracia-regional-brasil - acesso em 25/03/2011].

BARNES, John A. Redes sociais e processo político. In: FELDMAN-BIANCO, Bela. (org.) Antropologia das sociedades contemporâneas. São Paulo, Global, 1987, pp.159-194.

BraH, Avtar. Diferença, diversidade, diferenciação. Cadernos Pagu (26), Campinas-SP, Núcleo de Estudos de Gênero Pagu/Unicamp, 2006, pp.329-376.

. Phoenix, Ann. Ain't I a woman? Revisiting intersectionality. Journal of International Women's Studies (5:3), 2004, pp.75-86.

BUTLER, Judith. Fundamentos contingentes: o feminismo e a questão do pós-modernismo. Cadernos Pagu (11), Campinas-SP, Núcleo de Estudos de Gênero Pagu/Unicamp, 1998, pp.11-42.

Cuerpos que importan: sobre los límites materiales y discursivos del "sexo". Buenos Aires, Paidos, 2002.

Problemas de gênero: feminismo e subversão da identidade. Rio de Janeiro, Civilização Brasileira, 2003.

CAMARGO, Michelle de Alcântara. Lugares, pessoas e palavras: o estilo das minas do rock na cidade de São Paulo. Dissertação de Mestrado em Antropologia Social, Unicamp, 2010.

DAS, VEENA. Fronteiras, violência e o trabalho do tempo: alguns temas wittgensteinianos. Revista Brasileira de Ciências Sociais (4:40), São Paulo, 1999, pp.31-42.

FACCHINI, Regina. Entre umas e outras: mulheres, (homo)sexualidades $e$ diferenças na cidade de São Paulo. Tese de Doutorado em Ciências Sociais, Unicamp, 2008.

. Entrecruzando diferenças: mulheres e (homo)sexualidades na cidade de São Paulo. In: DíAz-BEníTEZ, Maria Elvira; FíGARI, Carlos Eduardo. (orgs.) Prazeres Dissidentes. Rio de Janeiro, Garamond, 2009, pp.309-341. 
FRANÇA, Isadora Lins. Sobre "guetos" e "rótulos": tensões no mercado GLS na cidade de São Paulo. Cadernos Pagu (28), Campinas-SP, Núcleo de Estudos de Gênero Pagu/Unicamp, 2007, pp.227-256.

GARRISON, Ednie Kaeh. U.S. Feminism - Grrrl Style! Youth (Sub)cultures and the Technologies of the Third Wave. Feminist Studies (26)1, Maryland, 2000, pp.141-170.

HEBDIGE, Dick. Subculture: the meaning of style. Londres, Methuen, 1979.

MELo, Érica. Cultura Juvenil Feminista Riot Grrrl em São Paulo. Dissertação de Mestrado em Sociologia, Unicamp, 2008.

ROSENBERG, Jessica; GAROFALO, Gitana. Riot Grrrl: Revolutions from within. Signs (23)3, Chicago, 1998, pp.809-841.

SouZA, Bruna Mantese. Os straight edges e suas relações com a alteridade em São Paulo. Dissertação de Mestrado em Antropologia Social, Universidade de São Paulo, 2006.

STRATHERN, Marilyn. For the Motion (1). The concept of society is theoretically obsolete. In: INGOLD, Tim. (org.) Key Debates in Anthropology. London, Routledge, 1996.

STRAW, Will. Scenes and sensibilities. Revista da Associação Nacional de PósGraduação em Comunicação [http://www.ecompos.com.br/e-compos acesso 06/08/2006].

VEGA, Alexandre P. Sexualidades em contexto urbano: uma análise da desconstrução de signos de identidade sexual entre jovens em São Paulo. Relatório de qualificação para Mestrado em Antropologia Social, São Paulo, 2007.

WALD, Gayle. Just a Girl? Rock Music, Feminism, and the Cultural Construction of Female Youth. Signs (23)3, Chicago, 1998, pp.585-610. 